NOTICE: This is the author's version of a work that was accepted for publication in Tectonophysics. Changes resulting from the publishing process, such as peer review, editing, corrections, structural formatting, and other quality control mechanisms may not be reflected in this document. Changes may have been made to this work since it was submitted for publication. A definitive version was subsequently published in Tectonophysics, Volume 601, August 2013, Pages 139-147. http://doi.org/10.1016/j.tecto.2013.05.005 


\section{Accepted Manuscript}

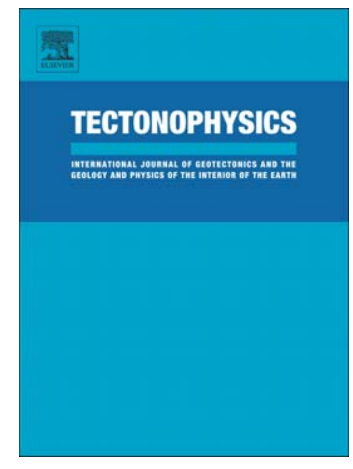

Estimating the mechanical anisotropy of the Iranian lithosphere using the wavelet coherence method

Ahmad Zamani, Jafar Samiee, Jon F. Kirby

PII:

S0040-1951(13)00299-0

DOI: $\quad$ doi: $10.1016 / j . t e c t o .2013 .05 .005$

Reference: $\quad$ TECTO 125889

To appear in: $\quad$ Tectonophysics

Received date: 16 July 2012

Revised date: $\quad 5$ April 2013

Accepted date: $\quad 8$ May 2013

Please cite this article as: Zamani, Ahmad, Samiee, Jafar, Kirby, Jon F., Estimating the mechanical anisotropy of the Iranian lithosphere using the wavelet coherence method, Tectonophysics (2013), doi: 10.1016/j.tecto.2013.05.005

This is a PDF file of an unedited manuscript that has been accepted for publication. As a service to our customers we are providing this early version of the manuscript. The manuscript will undergo copyediting, typesetting, and review of the resulting proof before it is published in its final form. Please note that during the production process errors may be discovered which could affect the content, and all legal disclaimers that apply to the journal pertain. 


\title{
Estimating the mechanical anisotropy of the Iranian lithosphere using the wavelet coherence method
}

\author{
Ahmad Zamani $^{1 *}$, Jafar Samiee ${ }^{1}$, Jon F Kirby ${ }^{2}$ \\ ${ }^{1}$ Department of Earth Sciences, College of Sciences, Shiraz University, Shiraz, Iran \\ ${ }^{2}$ Department of Spatial Sciences, Curtin University, GPO Box U1987, Perth, WA 6845, Australia \\ *Corresponding author: A. Zamani, E-mail: zamani_a_geol@yahoo.com , TellFax: 0098-71-2284572
}

\begin{abstract}
We calculated anisotropic wavelet coherence between Bouguer anomaly and topography in order to map the anisotropy of the effective elastic thickness of the Iranian lithosphere $\left(T_{e}\right)$. An orthotropic elastic plate model is used for inverting the anisotropic wavelet coherence to compute the mechanical anisotropy through the weak axis of the $\mathrm{T}_{\mathrm{e}}$. Anisotropy of the $\mathrm{T}_{\mathrm{e}}$-weak axis and the strength of the anisotropic parameter, namely the anisotropic coherence effect over the study area are estimated by restricting the rotated Morlet wavelet (fan wavelet) geometry over an azimuthal range of $90^{\circ}$. Large-scale $\mathrm{T}_{\mathrm{e}}$ variations have been shown to be associated with phenomena, such as mountain belts, subduction zones, craton boundaries, fault zones, and seismogenic regions. Although the correlation between the major tectonic features of the Iranian lithosphere and the distribution of the $\mathrm{T}_{\mathrm{e}}$-weak axis is not general or precise, in some regions, such as the Alborz, Kopeh Dagh, Zagros, and Makran orogenic belts, the weak axis has a uniform or slowly varying pattern which changes over their boundaries. A perpendicular alignment between seismic anisotropy measurements in Iran and the $\mathrm{T}_{\mathrm{e}}$-weak directions suggests a lithospheric origin for anisotropy. The correlation between averaged stress directions and the weak axis of the $T_{e}$ in Iran indicates that the present day stress field and the fossil strain are still related. Correlation between these factors suggests vertically coherent deformation of the lithosphere in Iran resulting from the multiply convergent orogenic processes. The complex mechanical anisotropy pattern of the Iranian lithosphere results from the interaction of many preexistent structures which dominantly control the mechanical anisotropy of the lithosphere.
\end{abstract}


Keywords: elastic thickness; flexural rigidity; weak direction; fan wavelet; gravity anomaly; topography; Iran

\section{Introduction}

The lithosphere is one of the most fundamental parts of the planet Earth in general and plays an important role in tectonic processes. As a result, Earth scientists from different background have studied the lithosphere intensively. The influences from petrologic and seismological researches, thermal and electrical modeling, and the mechanical behavior of the lithosphere, had already led to a realization of the need to reconcile different definitions of the lithosphere. This is even more the case where the lithosphere is affected by long geodynamic processes that produced significant heterogeneity in both crustal and mantle components.

According to Artemieva (2011) four boundary layers including the mechanical, rheological, thermal and chemical layers are closely related to the concept of the lithosphere. The classical definition of the "lithosphere" used in tectonic studies is close to the mechanical lithosphere. The elastic (or flexural) lithosphere provides the isostatic response of an elastic lithospheric plate to surface and/or subsurface loads and mechanically supports elastic stresses induced by plate bending (or flexure). Mechanical strength, as a function of elastic properties of the lithosphere, determines the pattern of deformation and structural architecture of the lithospheric plate in convergent plate boundaries (Audet et al., 2007). The best proxy for this is the wavelengthdependent effective elastic thickness $\left(T_{e}\right)$ of the lithosphere (Watts, 2001; Turcotte and Schubert, 2002) 


$$
T_{e}=\left[\frac{12 D\left(1-v^{2}\right)}{E}\right]^{1 / 3}
$$

where $\mathrm{D}$ is the flexural rigidity and $\mathrm{E}$ and $v$ are Young's modulus and Poisson's ratio respectively.

The relationship between the elastic thickness and mechanical thickness of the lithosphere is not straightforward. It depends on the rheology, temperature, strain rate and curvature of the lithospheric plate. Generally speaking, the elastic thickness is smaller than the mechanical thickness. Only in the case of bending or flexure of an elastic lithospheric plate, the two thicknesses are equal. In the case of a multilayered lithosphere, effective elastic thickness $\left(T_{e}\right)$ provides not the actual thickness of the mechanical lithosphere, but the thickness of the load-bearing layer which provides the integrated strength of the bending plate. Increasing the bending moment of plate curvature results in a decreasing effective flexural rigidity and, as a consequence, in a decreasing effective elastic thickness (Artemieva, 2011).

Topography can constrain the effective elastic thickness of the lithosphere. Joint interpretation of gravity and topography serves for determining the effective elastic thickness. Two spectral techniques, admittance and coherence analyses, can be used in the estimation of $\mathrm{T}_{\mathrm{e}}$ (Timoshinko and Woinwsky-Krieger, 1959; Forsyth, 1985). Forsyth has found that while the gravitational admittance depends on the ratio between the subsurface (buried) and the surface (topography) loads, the coherence calculated from the gravity anomalies is not sensitive to it and thus better suits calculations of flexural characteristics and the $T_{e}$ of the lithosphere. Here subsurface loads include variations in the thickness and density of the lithospheric plate and surface loads include topography. 
Large-scale tectonic phenomena, such as mountain ranges, subduction zones, craton boundaries, fault zones, and the magnitude of seismicity, are associated with large variations of $\mathrm{T}_{\mathrm{e}}$ (Lowry and Smith, 1995; Tassara et al., 2007; Kirby and Swain, 2009; Audet and Bürgmann, 2011). Geophysical and geological observations indicate that most lithospheric materials display physical anisotropy on all scales. (Simons et al., 2000; Simons and van der Hilst, 2003; Audet and Mareschal, 2004). Temperature, composition and state of stress vary in all directions in the lithosphere, and these parameters have the primary effect on $T_{e}$ (Lowry and Smith, 1995). Gravity-topography coherence that was originally formulated by Frosyth (1985) and discussed in Watts (2001) is a measure of the correlation between gravity anomalies and topography. One of the most efficient methods to calculate $T_{\mathrm{e}}$ is through the coherence between Bouguer anomaly and topography. Previously, this wavelength-dependent function was calculated based on Fourier transform methods whose resolution depends on window sizes (Simons et al., 2000; Kirby and Swain, 2004; Pérez-Gussinyé and Watts, 2005). Recently many researchers have used waveletbased methods which enable them to recover $\mathrm{T}_{\mathrm{e}}$ with high spatial resolution (Kirby and Swain, 2004; Audet and Mareschal, 2007; Kirby and Swain, 2008, 2010).

Traditionally, the observed coherence comprised with theoretical coherence which is calculated from isotropic and uniform thin elastic plate model in order to determine $T_{e}$ (Watts, 2001). In this model the response to applied load is equal in all directions. However, given the anisotropic nature of the lithosphere and the variables that affect $T_{e}$, it is clear that loading response is not generally equal in all directions (Kirby and Swain, 2006). Several researchers have used two dimensional (2D) maximum entropy or multitaper technique in order to detect the anisotropy in observed coherence but they used isotropic thin elastic plate model to interpret their observed coherences (Lowry and Smith, 1995; Simons et al., 2000, 2003; Audet and 
Mareschal, 2004). Swain and Kirby (2003) used an anisotropic thin elastic plate for interpretation of observed coherence in central Australia. Kirby and Swain (2006) presented a wavelet approach by using such a plate model for anisotropic estimates of $\mathrm{T}_{\mathrm{e}}$ and mapping the mechanical anisotropy of the lithosphere.

In this study a high-resolution map of the mechanical anisotropy of the Iranian lithosphere is presented. The results have been compared with other geophysical and geological data in order to understand the state of lithospheric deformation in Iran.

\section{Tectonic setting}

Iran occupies part of the Alpine - Himalayan mountain chain that stretches across much of Southwest Asia and the Middle East. Seismological studies indicate that Iran is underlain by a thin lithosphere and warm upper mantle (Maggi and Priestley, 2005). The tectonic evolution of the Iranian lithosphere is a spectacular example of young Tertiary orogenic event and of earlier obduction/subduction processes. The distinct features of the Iranian lithosphere are topographic expressions of the subsurface subduction and deformations that the lithospheric rocks have undergone. Lithospheric deformation occurs as a result of the multiply convergent orogen between Arabian, Eurasian, and Indian plates (Fig.1).

Geological studies show that collision between the Arabian plate and the Central Iranian Blocks (CIBs) started before 23-25 Ma, in the north-west of the Zagros Fold and Thrust Belt (ZFTB) and continued to the south-east in younger times like a zip fastener closing to SE (Agard et al., 2005). The Zagros Fold and Thrust Belt extends over $2000 \mathrm{~km}$ from the north-east of Turkey to the Minab Fault Zone (MFZ). The belt is structurally characterized by NW-SE trending high-angle reactivated thrust faults and double plunging folds associated with them and 
NS-trending strike-slip faults (Paul et al., 2010). The Kazeroun Fault Zone (KFZ) separates the north-west of the belt from its south-east part. Like all the other N-S trending strike-slip faults, the Kazeroun Fault Zone was probably penetrated into the Pan-African Arabian basement before the opening of Tethys (Paul et al., 2010). The Zagros Fold and Thrust Belt is separated by the NW-SE trending Sanandaj-Sirjan Metamorphic Belt (SSMB) from Central Iranian Blocks and Urumieh-Dokhtar Magmatic Belt (UDMB) (Fig. 1). The degree of deformation increases from the Persian Gulf where the geological units remain horizontal to Sanandaj-Sirjan Metamorphic Belt (Alavi, 1994, 2004). Seismic tomography and shear wave splitting studies show both the Sanandaj-Sirjan Metamorphic Belt and the Zagros Fold and Thrust Belt belts are underlain by the Arabian lithospheric mantle (Kaviani et al., 2009).

After closure of the Paleo-Tethys ocean in the north and Neo-Tethys in the south, the ongoing collision was responsible for significant strain in the lithosphere in Iran during the past 5 My (Kaviani et al., 2009). Continental shortening and strike-slip activity as a result of oblique convergence between Arabia and Eurasia are the dominant deformation mechanisms in all of the study area except in the south-east of Iran where the subduction of oceanic lithosphere still occurs in the Makran Subcuction Zone (MSZ). Most of the deformation is limited to orogenic belts, the Alborz and Kopeh Dagh in the north, and the Zagros in the south (Jackson et al., 1995; Vernant et al., 2004). Currently the convergence rate between Arabia and Eurasia is $22 \pm 2 \mathrm{~mm} / \mathrm{yr}$ (Vernant et al., 2004). Highly strained tectonic zones experience mainly aseismic plastic flow deformation in southern Iran and seismic deformation in northern Iran. A major contrast in deformation is observed between the Zagros Fold and Thrust Belt in the south and the Alborz and Kopeh Dagh regions in the north of Iran. Jackson and McKenzie (1988) and Masson et al. (2005) proposed values ranging between 3-15 per cent for seismic deformation in the Zagros and 
values ranging between 30-100 percentage for seismic deformation in the Alborz and Kopeh Dagh mountain ranges. This indicates that the seismic deformation is negligible in southern Iran with respect to the total strain. Therefore, the northern part of Iran is seismically deformed while deformation in southern part is more or less aseismic.

The present tectonic frame of the Alborz mountain belt was formed from the collision of the Central Iranian Blocks with Eurasia (Zanchi et al., 2006). The belt extends over $960 \mathrm{~km}$ with nearly $100 \mathrm{~km}$ width and separates the Caspian basin from the Central Iranian Blocks (Zamani and Hashemi, 2000; Zamani and Atabi, 2009). The trend of these mountains curves toward the north and in the east merges with the NW trended Kopeh Dagh (fig. 1). The range has an average crustal thickness about $35 \mathrm{~km}$. The Kopeh Dagh range extends for a distance of $700 \mathrm{~km}$ across the north-east of Iran and defines the present day boundary between Central Iranian Blocks and the Turan platform. The Kopeh Dagh range is a post Miocene intracontinental fold-and-thrust belt (Zamani et al., 2008).

The Central Iran Blocks are an assemblage of continental blocks which are separated by large scale N-S trending strike-slip faults. Seismic anisotropy studies suggest that these faults extend to the base of the lithosphere (Kaviani et al., 2009). Each block differs not only in structural character and intensity of deformation but also in the age of magmatism and metamorphism (Nadimi, 2006). The history of deformation of the Central Iranian Blocks is related to Pan African orogeny that was ended with the intrusion of granites and alkaline volcanism. These rocks are covered by Lower Cambrian sedimentary rocks (Stö cklin, et al., 1964). There is no evidence of major magmatism or folding in The Central Iranian Blocks until Late Paleozoic times (Berberian, 1983). Most of the deformation due to the ongoing convergence between Arabia and Eurasia is accommodated in strike-slip activities in this region. The Central Iranian 
Blocks show internal deformation of less than $2 \mathrm{~mm} / \mathrm{yr}$ so is most likely characterized by coherent plate motion (Vernant et al., 2004). The East Iran belt associated with the Sistan suture zone separates the Central Iranian Blocks from the Hilmand Blocks (Fig. 1).

\section{Method of analysis}

The rotated Morlet wavelets (fan wavelet) is one of the most popular transformations that provides the space-frequency representation for gravity-topography signals (see for example, Kirby, 2005 ; Kirby and Swain, 2004 ; 2006 ; Audet et al., 2007). Use of a wavelet-based approach in calculating the lithospheric elastic thickness, $T_{e}$, can avoid the problem of the window's size in Fourier based methods. Fourier coefficients are dependent on wavenumber only, whereas wavelet coefficients are functions of both wavenumber and spatial coordinates (Grossman and Morlet, 1984; Kirby and Swain, 2004; Tassera et al., 2007). The fan wavelet method was developed for computing the variations in $\mathrm{T}_{\mathrm{e}}$. It can reproduce the power spectrum very similarly to Fourier methods (Kirby, 2005). The fan wavelet transform is formed by a superposition of rotated Morlet wavelet transforms (Kirby and Swain, 2004; Kirby, 2005) and is calculated through the fast Fourier transform.

Computation of wavelet anisotropy begins with calculating the Morlet wavelet transform of the Bouguer anomaly and topography signals:

$$
\begin{aligned}
\tilde{b}_{s \mathrm{X} \theta} & \equiv \tilde{b}^{M}(s, \mathrm{X}, \theta)=F^{-1}\left\{\hat{b}(K) \hat{\psi}_{s, \theta}^{M^{*}}(K)\right\} \\
\tilde{t}_{s \mathrm{X} \theta} & \equiv \tilde{t}^{M}(s, \mathrm{X}, \theta)=F^{-1}\left\{\hat{t}(K) \hat{\psi}_{s, \theta}^{M^{*}}(K)\right\}
\end{aligned}
$$

where $\mathrm{X}=(\mathrm{x}, \mathrm{y})$ is the translation parameter or the space-domain position vector (i.e., the location of the window). In this case, $x$ and $y$ are longitude and latitude of each geographic location of the study area respectively; s is the dilation parameter ('scale') and $\theta$ is the rotational parameter 
which determines the resolving azimuth of the fan wavelet; $\mathrm{F}^{-1}$ is the inverse 2D Fourier transform; $\hat{b}(K)$ and $\hat{t}(K)$ are the 2D Fourier transform of Bouguer anomaly and topography signals respectively. $\mathrm{K}(\mathrm{u}, \mathrm{v})$ is the $2 \mathrm{D}$ wavenumber, where $\mathrm{u}$ and $\mathrm{v}$ are the wavenumbers in the $\mathrm{x}$ and y- directions. $\hat{\psi}_{s, \theta}^{M^{*}}(K)$ are complex conjugates of 2D Fourier transforms of the daughter wavelets

$$
\hat{\psi}_{s, \theta}^{M}(K)=s e^{-\left[\left(s u-\left|K_{0}\right| \cos \theta\right)^{2}+\left(s v-\left|K_{0}\right| \sin \theta\right)^{2}\right] / 2}
$$

where $\left|K_{0}\right|$ is the central frequency. Scale (s) determines the width (dilation) of the fan wavelet in X-space, and hence controls resolution. The parameter scale in the wavelet analysis is similar to the scale used in maps. As in the case of maps, large scales (low frequencies) correspond to non-detailed global view of the signal that usually spans the entire signal. For small scales (high frequencies), on the other hand, the wavelet transform reveals a detailed view or hidden pattern in the signal that usually continued a short distance. In other words, scales $>1.0$ dilates the signal and the wavelet coefficients reveal long wavelengths, while scales $<1.0$ compresses the signal and the wavelet coefficients depict short wavelengths in the data. Therefore, wavelet transforms are local in both space-domain or equivalently in the wavenumber-domain (via translations) and in frequency-domain (via dilations). In this respect, the wavelet transform is similar to a series of band-pass filters. It is the combination of this translation with the dilation that allows the frequency characteristics at each location of the gravity and topography signals to be revealed.

The rotated Morlet wavelet (fan wavelet) transforms are taken at some starting azimuth or direction. The degree of directionality of the fan wavelet (side to side) has been advocated in azimuth. For the study of anisotropic effective elastic thickness, the auto- and cross-spectra of the gravity and topography wavelet coefficients should be averaged over an azimuthal extent $\theta$. 
As a result, the averaged auto- and cross-spectra and the resulting wavelet coherence become directional and the anisotropy in the $T_{e}$ can be revealed (Kirby and Swain, 2006). In order to avoid azimuthal over- and under-sampling, the azimuthal increment or interval $\delta \theta$ between successive transforms of the rotated Morlet wavelets (fan wavelet) should have a value of $\delta \theta=\sqrt{\ln (4 / 3) \ln (2 / \pi)} \approx 16.3^{\circ}$. The necessary number of rotated Morlet wavelet (fan wavelet) transforms which depends on the total azimuthal extent $\theta$ of the fan is given by $\mathrm{N}_{\theta}=\operatorname{int}(\theta / \delta \theta)$. For determining the mechanical anisotropy of $\mathrm{T}_{\mathrm{e}}$ the procedure of Kirby and Swain (2006) is used in this paper. For this purpose, the auto- and cross-spectra of the gravity and topography wavelet coefficients are averaged at six central (or resolving) azimuths, spanning the range of $0^{\circ}$ to $150^{\circ}$ in increments of $30^{\circ}$ to ensure good azimuthal coverage. For every central azimuth each averaging auto- and cross-spectra were calculated over $\mathrm{N}_{\theta=} 5$ azimuths, rather than averaging the wavelet coefficients themselves (Eqs. 5-7). The calculations were performed for many values of scale by restricting the fan wavelet over an azimuthal extent of $\theta=90^{\circ}$.

The scales are usually chosen to span the entire bandwidth of the gravity and topography signals. Finally the anisotropic wavelet coherence $\left(\gamma_{w}^{2}(s, X, \theta)\right)$ for each fan is computed (Eq. 8). Therefore, six anisotropic estimates of the rotated Morlet wavelet coherence were obtained at each geographic location, $\mathrm{X}=(\mathrm{x}, \mathrm{y})$, of the study area.

$$
\begin{aligned}
& \left\langle\begin{array}{ll}
\tilde{b}_{s \mathrm{X} \theta} & \tilde{b}_{s \mathrm{X} \theta}^{*}
\end{array}\right\rangle_{\theta} \equiv \frac{1}{N_{\theta}} \sum_{n=1}^{N_{\theta}} \begin{cases}\tilde{b}_{s \mathrm{X} \theta} & \left.\tilde{b}_{s \mathrm{X} \theta}\right\}_{n}\end{cases} \\
& \left\langle\tilde{t}_{s \mathrm{X} \theta} \quad \tilde{t}_{s \mathrm{X} \theta}^{*}\right\rangle_{\theta} \equiv \frac{1}{N_{\theta}} \sum_{n=1}^{N_{\theta}} \begin{cases}\tilde{t}_{s \mathrm{X} \theta} & \left.\tilde{t}_{s \mathrm{X} \theta}^{*}\right\}_{n}\end{cases}
\end{aligned}
$$

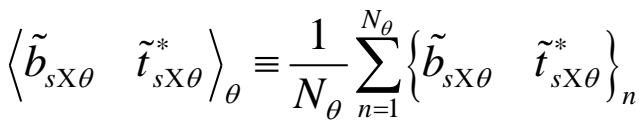




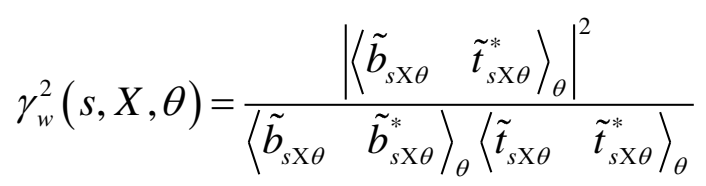

According to Swain and Kirby (2003) and Kirby and Swain (2006) the anisotropy of an orthotropic elastic plate model may be parameterized by two different orthogonal elastic thicknesses, $\mathrm{T}_{\max }$ and $\mathrm{T}_{\min }$. With such a model the observed coherence can be interpreted in an anisotropic manner. The scheme is to calculate the anisotropic effective elastic thickness, $\mathrm{T}_{\mathrm{e}}$, using the coherence method. Anisotropic parameters were calculated by iteratively minimizing the misfit between theoretical and observed coherences. As a result, variations in the magnitude of the anisotropic parameter and weak mechanical strength direction (i.e., maximum coherence direction) can be estimated (Kirby and Swain, 2006).The dimensionless anisotropic parameter, called the anisotropic coherence effect 'ACE' in this paper, is an indicator of the strength of the mechanical anisotropy of the elastic lithosphere

$$
A C E=\left(T_{\max }-T_{\min }\right) / T_{\max }=\left(T_{\max } / T_{\min }\right)-1
$$

while the per cent anisotropic coherence effect 'PACE' is given by

$$
P A C E=100\left(T_{\max }-T_{\min }\right) / T_{\max }
$$

where $\mathrm{T}_{\max }$, and $\mathrm{T}_{\min }$, are the maximum and minimum effective elastic thicknesses of the lithosphere, respectively.

In this paper the fan wavelet coefficients of the gravity and topography signals, their autoand cross-spectra, together with the anisotropic wavelet coherence were estimated at $95 \%$ confidence level. The data served as the basis on which the mechanical anisotropy map of the lithosphere in Iran has been constructed (Fig. 3) either were given or could be directly inferred from the literature. 
The Bouguer gravity anomaly data were taken from Dehghani and Markis (1984) work in which the Bouguer anomalies are evaluated from 10,000 gravity stations in Iran (Fig. 2). The Bouguer and terrain reductions were computed on a spherical earth using a constant rock density of $2.67 \mathrm{gr} / \mathrm{cm}^{-3}$. Elevation data were obtained from the global elevation model of Smith and Sandwell (1997). The grids interval is $40 \mathrm{~km}$ and both data sets were projected onto a Lambert Conformal Conic grid on the WGS84 ellipsoid with $54^{\circ} \mathrm{E}$ central meridian.

The present status of geophysical and geological maps of Iran is not sufficiently advanced to make more effective use of the present data. Furthermore, it is important to recognize that the anisotropic parameter and the variations of the $\mathrm{T}_{\mathrm{e}}$-weak direction presented in this paper are based purely on the gravity-topography wavelet coherence analysis. Therefore correspondences and differences between $T_{\mathrm{e}}$-map generated in this paper and a given conventional map must receive careful thought.

\section{Results and discussion}

In the wavelet coherence analysis, anisotropy in the coherence normally appears at different wavelength regimes. Therefore, the uncertainty of the observed wavelet coherence is assumed to be proportional to wavenumber. In order to reduce the uncertainty of an estimated coherence value the data are weighted by 1/wavenumber (Kirby and Swain, 2006; Audet and Mareschal, 2007). At long wavelengths, any anisotropy results from deep lithospheric structures but at short wavelengths, they reflect shallower structures such as active surface fault zone (Simons and van der Hilst, 2003; Audet and Mareschal, 2007). For short-wavelength surface and buried loads, the coherence approaches 0.00 . This is because the lithosphere appears strong at these wavelengths, regardless of effective elastic thickness. In this case surface and buried loads cause a small 
flexure and make little contribution to Bouguer gravity anomaly. Therefore, the correlation between the Bouguer gravity anomaly and topography is poor and there is no information on gravity from the observed topography. For long-wavelength loads, the lithosphere appear weak and the coherence approaches 1.00 , such loads cause a large flexure and contribute significantly to the Bouguer gravity anomaly. In this case the correlation between Bouguer gravity anomaly and the topography is good (Watts, 2001). Generally speaking, the lithosphere is behaving as a filter in the way that it responds to surface loads; suppressing the short-wavelength deformation associated with local models of isostasy and passing the long wavelength associated with the bending of lithosphere. Here we take mechanical anisotropy, or $\mathrm{T}_{\mathrm{e}}$-weak direction, as result of the long-wavelength anisotropic wavelet coherence (Kirby and Swain, 2006).

Fig. 3 shows the weak axes of mechanical anisotropy of the lithosphere (i.e., the $\mathrm{T}_{\mathrm{e}}$-weak direction) in Iran, where the axis length, $\left.\left(\mathrm{T}_{\max }-\mathrm{T}_{\min }\right) / \mathrm{T}_{\max }\right)$, is proportional to the magnitude of anisotropy. Response of the lithosphere to the loading is not equal in all directions. In the other words direction of axes in Fig. 3 shows the direction of minimum flexural rigidity where the lithosphere displays a maximum bending under the loading. The magnitude of anisotropy correspond to the length of the axes which shows the relative differences between maximum directional effective elastic thickness $\left(\mathrm{T}_{\max }\right)$ and minimum directional effective elastic thickness $\left(\mathrm{T}_{\min }\right)$ and expressed as per cent anisotropic coherence effect (PACE). Anisotropy is detected in all of the study area. Although the correlation between the major tectonic features of the Iranian lithosphere and the distribution of the $\mathrm{T}_{\mathrm{e}}$ weak axis is not common or precise, in some regions, such as the Zagros, Makran, Alborz, and Kopeh Dagh orogenic belts, the weak axis has a uniform or slowly varying pattern which changes over these structures. In the Urumieh-Dokhtar Magmatic Belt and the western part of the central Iran the orientation of $\mathrm{T}_{\mathrm{e}}$-weak axes changes 
abruptly with local structures, but it clearly shows distinct uniform clusters in the north and the south of the study area.

The resulting $\mathrm{T}_{\mathrm{e}}$-weak direction indicates that Zagros Fold and Thrust Belt and the SanandajSirjan Metamorphic Belt are separated by the Kazeroun Fault Zone in two sectors. This demonstrates the lithospheric nature of this fault zone (Paul et al., 2010). In NW, the weak direction of anisotropy is aligned NE-SW and its magnitude is high (between 80 to $100 \%$ of anisotropy). To the Kazeroun fault area, the magnitude of anisotropy is reduced to less than $10 \%$. The SE part of the region between the Kazeron and Minab Fault Zone (i.e., the transition of the Zagros Fold and Thrust Belt to Makran Subcuction Zone) which are dominated by northtrending right lateral strike-slip fault activity (Sepehr and Cosgrove, 2003), the axis trends are NS and magnitude of anisotropy are between $30 \%$ to $60 \%$. In both sections, the weak axes are aligned almost perpendicular to the structural trend imparted by thrust faults and fold axis. The pattern of mechanical anisotropy does not change along the Zagros Fold and Thrust Belt and SSMZ which suggests that they have the same lithospheric mantle (Arabian lithosphere) (Kaviani et al., 2009). In the Makran Subcuction Zone the weak axis is parallel to the direction of the Makran subduction zone, which is the predicted pattern in subduction zones (fig. 3) (Audet et al., 2007).The magnitude of anisotropy in the Makran subduction zone are between $30 \%$ to $50 \%$.

In the east and central parts of the Alborz mountain belt, the weak axes are perpendicular to the structural trends. The magnitude of anisotropy in these parts shows $70 \%$ to $100 \%$ of anisotropy which is much higher than in the west and the Talesh area (40\% to $50 \%$ of anisotropy) (fig. 1). The westward motion of the South Caspian Basin relative to both Iran and Eurasia may have strongly deformed by west trending underthrusting of the basin beneath the Talesh range and the western Alborz (Jackson et al., 2002). Here the weak axes are aligned 
parallel to the range. There is a sharp change in weak axis direction at the boundary between the eastern Alborz and Kopeh Dagh ranges where the NW trended weak axes of the former suddenly change to a NE alignment. The direction of the weak axes is aligned perpendicular to the structural trend of the Kopeh Dogh Mountains. The magnitude of anisotropy at the boundary between Kopeh Dagh and Alborz increased from 20\% through in 50-60\% in the east of the range.

The pattern of mechanical anisotropy in the Central Iranian Blocks is more complex than in other regions. In the west and east the axes of weak direction are aligned orthogonal to the faults and here the magnitude of anisotropy is high (60-70\%). However, within each block the magnitude is much lower (10-20\%) and the response of the lithosphere is tending to isotropic behavior. The weak axes within the Lut block are aligned perpendicular to the trend of the block. Rapid change of weak axis and their magnitude along the major strike-slip faults in Central Iranian Blocks indicate the lithospheric nature of these faults (fig. 2). In the Sistan suture zone which decorated with ophiolites the weak axis are perpendicular to the faults and ophiolites belts and magnitude of anisotropy are between $70-80 \%$.

\subsection{Stress, seismic and mechanical anisotropy}

Mechanical anisotropy is an integrated measurement of the anisotropic rheology of the lithosphere (Audet et al, 2007). Rheology of the different layers of the lithosphere governs the style of deformation, within and on its surface. Tectonic stress is responsible for deformation in the brittle part of the crust. Seismic anisotropy reflects the deformation in the sublithospheric mantle and the upper-most part of the asthenosphere associated with mantle flow. It is commonly accepted that $\mathrm{T}_{\mathrm{e}}$ values in the lithospheric plates correspond to its "fossil" rheological state, build 
up at the time of loading (Simons and van der Hilst, 2003). By contrast, stress derivation from earthquake focal mechanisms provide a snap-shot of present state of stress in seismogenic regions which reflects their present rather than "fossil" rheological state.

Mechanical anisotropy as a measure of fossil strain is key to understanding past lithospheric deformation. Regional stress fields in the lithosphere are generally associated with plate driving forces but local variations of stress direction exist at all scales. Local stress direction is associated with specific geological structures (Zoback, 1992). In order to avoid such variations, the mechanical anisotropy is compared with averaged stress regimes in the study area (Kirby and Swain, 2006).

The state of stress within each tectonic province and subprovince of the collision zone of Arabia and Eurasia in Iran is calculated based on a systematic inversion of available focal mechanisms of earthquakes (Zamani et al., 2008; Zamani, 2009). The earthquake focal mechanisms which were used to compute seismotectonic stress in Iran came from online sources and the literature (Chandra, 1981; McKenzie, 1972; Jackson and McKenzie, 1984; Nowroozi, 1972; Jackson and Fitch, 1979; Priestley et al., 1994; Jackson et al., 2002). The online sources such as CMT, (Centroid Moment Tensor, available online at: http://www.seismology. harvard.edu/CMT search. html ) and USGS ( USGS, United States Geology Survey, 2006 , available online at: http:// earthquake.us-gs.gov/rapid solution). The angular uncertainty of $\mathrm{T}_{\mathrm{e}}$ anisotropy and averaged stress directions is approximately $\pm 10^{\circ}$ (Kirby and Swain, 2006; Zamani et al., 2008).

Fig. 4 compares the averaged stress data with weak directions averaged over $160 \times 160 \mathrm{~km}$, and 320 x $320 \mathrm{~km}$ windows. Fig. 5 shows a histogram of angular differences between stress axes and weak directions. $68 \%$ of all mean stress axes in the study area are within $15^{\circ}$ of the weak 
directions, with $87 \%$ less than $22.5^{\circ}$, which indicates a good correlation between mean stress axes and $\mathrm{T}_{\mathrm{e}}$-weak directions.

Seismic anisotropy results from lattice preferred orientation (LPO) of olivine, the dominant mineral in the mantle (Park and Levin, 2002). Seismic anisotropy is measured either from surface waves which have a better depth resolution but poor spatial resolution, or from shear wave splitting of core phases which have better spatial resolution but the poorer depth resolution (Silver, 1996). Seismic anisotropy is aligned with the shear direction as the result of mantle flow, or can be aligned perpendicular to the horizontal shortening (Silver, 1996). If all levels of the lithosphere deform coherently then seismic anisotropy should be aligned with transpressional and extensional structures or perpendicular to large-scale compressional structures such as orogenic belts (Simons and van der Hilst, 2003).

Seismic anisotropy in Iran is measured from earthquake records of core-refracted phases (SKS, SKKS and PKS) (Kaviani et al., 2009). Shear wave splitting has a good spatial resolution but reflects the anisotropy of the whole upper mantle. Time lags under $0.5 \mathrm{~s}$ is considered as a null measurement (Silver, 1996). The mean standard errors in seismic anisotropy measurements of Iran are generally smaller than $\pm 20^{\circ}$ for azimuth and \pm 0.3 s for time delay (Kaviani et al., 2009). From northeast of the Urumieh-Dokhtar Magmatic Belt to Central Iranian Blocks, the seismic anisotropy shows a northwest-southeast trend with an average lag time of $1.12 \pm 0.3 \mathrm{~s}$. A northeast-southwest seismic anisotropy trend with an average lag time of $1.10 \pm 0.3 \mathrm{~s}$ has been detected in the northern Central Iranian Blocks and western Kopeh Dagh (Kaviani et al., 2009).Fig. 6 shows the comparison between weak axis (averaged over an 80 x $80 \mathrm{~km}$ area) and non- null measurements of seismic anisotropy (Kaviani et al., 2009). Similar to the mechanical anisotropy, seismic anisotropy tends to uniformity within each province but varies from one 
province to another. In all regions except the west of the southern Caspian basin seismic anisotropy directions are aligned at large angles to or perpendicular to the weak axis direction which suggests the same origin of anisotropy. Seismic anisotropy in Iran originates in the lithospheric mantle (Kaviani et al., 2009). In the western part of the southern Caspian basin, seismic and mechanical anisotropy is parallel (Fig. 5). In this area, the junction of old oceanic and continental crust may be the cause of rheological weakness.

\section{Conclusions}

The correlation between the gravity and topography signals of Iran was estimated using the rotated Morlert wavelet (fan wavelet) coherence method. Variations of the weak mechanical strength direction $\left(\mathrm{T}_{\mathrm{e}}\right.$-weak axis) that coincide with the maximum coherence direction were calculated. The high-resolution mechanical anisotropy map of Iran reveals deep structures of the lithosphere. Throughout the study area the weak axes of $\mathrm{T}_{\mathrm{e}}$ or the direction of minimum flexural rigidity are almost perpendicular to the main tectonic trends of the orogenic belts. Furthermore, the magnitude of the anisotropic parameter, namely the anisotropic coherence effect (ACE) over these regions is high. Due to the collision and convergent process, these areas are heavily strained and mechanically weak (Simons and van der Hilst, 2003). These processes are responsible for faulting, folding and magmatic activity in all of the study area. These long term activities affect the whole lithosphere with significant strain which is recorded as fossil strain or mechanical anisotropy.

The correlation between the mechanical anisotropy and averaged stress directions suggest that the same stress field affected the study area during the last orogenic phase (the late Eocene $=\sim 34 \mathrm{Ma}$ ). The correlation between tectonic stress and seismic and mechanical anisotropy 
suggest that vertically coherent deformation for the lithosphere in Iran resulted from the process of orogenic convergence. The mechanical anisotropy of Iran displays a complex pattern as the result of the interaction of many pre-existent structures which is dominantly controlled the mechanical anisotropy of the lithosphere. The study of the mechanical anisotropy could shed some light on the rheological behavior of the lithospheric plate and its role in the development of the orogenic belts.

\section{Acknowledgments}

The authors thank the editor and the two anonymous reviewers, whose helpful comments greatly improved this contribution. This work was supported by the Center of Excellence for Environmental Geohazards, and the Research Council of Shiraz University.

\section{References}

Agard, P., Omrani, J., Jolivet, L., Mouthereau, F., 2005. Convergence history across Zagros (Iran): constraints from collisional and earlier deformation. Int. J. Earth Sci. 94, 401-419. doi:10.1007/s00531-005-0481-4.

Alavi, M., 1991. Tectonics map of the Middle East, scale 1:5,000000. Geological Survey of Iran, Tehran.

Alavi, M., 1994. Tectonics of the Zagros orogenic belt of Iran: new data and interpretations. Tectonophysics. 229, 211-238.

Alavi, M., 2004. Regional stratigraphy of the Zagros fold-thrust belt of Iran and its pro foreland evolution. Am. J. Sci. 304, 1-20. 
Artemieva, I., 2011. The Lithosphere: An Interdisciplinary Approach. Cambridge University Press. 773 pp.

Audet, P., Mareschal, J.C., 2004. Anisotropy of the flexural response of the lithosphere in the Canadian Shield, Geophys. Res. Lett. 31, L20601. doi:10.1029/2004GL021080.

Audet, P., Mareschal, J.C., 2007. Wavelet analysis of the coherence between Bouguer gravity and topography: Application to the elastic thickness anisotropy in the Canadian Shield. Geophys. J. Int. 168, 287-298.

Audet, P., Jellinek, A.M., Uno, H., 2007.Mechanical controls on the deformation of continents at convergent margins. Earth Planet. Sci. Lett. 264, 151-166.

Audet, P., Bürgmann, R., 2011. Dominant role of tectonic inheritance insupercontinent cycles. Nature 436, 381-384.

Berberian, M., 1983. Continental Deformation in the Iranian Plateau. Report, 52. Geological Survey of Iran.

Chandra, U., 1981. Focal mechanism solutions and their tectonic implications for the eastern Alpine-Himalayan region. In: Gupta, H.K., Delany, F.M. (Eds.), Zagros-Hindu Kush-Himalaya Geodynamic Evolution, Geodynam-ics Series, vol. 3. Co-published by the Am. Geophys. Union Washington DC and the Geol. Soc. Am. Boulder, Co., pp. 243-271.

Dehghani, G.A., Makris, J., 1984. The Gravity Field and Crustal Structure of Iran. N. Jb.

Geol.Paläont. Abh., 168, Stuttgart, 215-229.

Forsyth, D.W., 1985. Subsurface loading and estimates of the flexural rigidity of continental lithosphere. J. Geophys. Res. 90 (B14), 12623-12632.

Nadimi, A., 2006. Evolution of the Centeral Iranian basement. Gondwana Resesarch. 12, 324333. 
Nowroozi, A.A., 1972. Focal mechanisms of Earthquakes in Persia, Turkey, West Pakistan, and Afghanistan and plate tectonics of the Middle East. Bull. Seismol. Soc. Am. 62, 823-850.

Priestley, K., Baker, C., Jackson, J., 1994. Implication of earthquake focal mechanism data for the active tectonics of the South Caspian Basin and surrounding regions. Geophys. J. Int. 118, $111-141$.

Jackson, J.A., Fitch, T.J., 1979. Seismotectonic implications of relocated after-shock sequences in Iran and Turkey. Geophys. J. R. Astr. Soc. 57, 209-229.

Jackson, J.A., McKenzie, D.P., 1984. Active tectonics of the Alpine-Himalayan belt between western Turkey and Pakistan. Geophys. J. R. Astr. Soc. 77, 185-264.

Jackson, J.A., McKenzie, D.P., 1988. The relationship between plate motions and seismic moment tensors, and the rates of active deformation in the Mediterranean and Middle East. Geophysical Journal, 93, 45-73.

Jackson, J., Haines, J., Holt, W., 1995. The accommodation of Arabia-Eurasia plate convergence in Iran. J. Geophys. Res. 15, 205-15219.

Jackson, J., Priestley, K., Allen, M., Berberian, M., 2002. Active tectonics of the South Caspian Basin.Geophys. J. Int. 148(2), 214-245.

Kaviani, A., Hatzfeld, D., Paul, A., Tatar, M., Priestley, K., 2009. Shear-wave splitting, lithospheric anisotropy, and mantle deformation beneath the Arabia-Eurasia collision zone in Iran. Earth and Planetary Science Letters. 286, 371-378.

Kirby, J.F., 2005. Which wavelet best reproduces the Fourier power spectrum?.Computers and Geosciences. 31(7), 846-864.

Kirby, J.F., Swain, C.J., 2004. Global and local isostatic coherence from the wavelet transform. Geophysical Research Letters. 31(24), L24608, doi: 10.1029/2004GL021569. 
Kirby, J.F., Swain, C.J. 2006. Mapping the mechanical anisotropy of the lithosphere using a 2D wavelet coherence, and its application to Australia. Phys. Earth Planet. Int. 158, 122-138.

Kirby, J.F., Swain, C.J., 2008. An accuracy assessment of the fanwavelet coherence method for elastic thickness estimation. Geochemistry, Geophysics, Geosystems, 9(3), Q03022.doi: 10.1029/2007GC001773. (Correction. 2008. Geochemistry, Geophysics, Geosystems. 9(5), Q05021, doi: 10.1029/2008GC002071).

Kirby, J.F., Swain, C.J., 2009. A reassessment of spectral Te estimation in continental interiors: The case of North America. J. Geophys. Res. 114, B08401.

Kirby, J.F., Swain, C.J., 2010. Improving the spatial resolution of effective elastic thickness estimation with the fan wavelet transform. Computers and Geosciences.

doi:10.1016/j.cageo.2010.10.008

Lowry, A.R., Smith, R.B., 1995. Strength and rheology of the western US Cordillera. J.

Geophys. Res. 100, 17947-17963.

McKenzie, D., 1972. Active tectonics of the Mediterranean region. Geophys. J. R. Astr. Soc. 30, $109-185$.

Maggi, A., Priestley, K., 2005. Surface waveform tomography of the Turkish-Iranian plateau. Geophys. J. Int. 160, 1068-1080.

Masson, F., Chéry, J., Martinod, J., Hatzfeld, D., Vernant, P., Tavakoli, F., Ashtiani, A., 2005. Seismic versus aseismic deformation in Iran inferred from GPS and seismicity data, Geophys. J. Int. $160,217-226$.

Park, J., Levin, V., 2002. Seismic anisotropy: Tracing plate dynamics in the mantle. Science. 296, 485-489. 
Paul, A., Hatzfeld, D., Kaviani, A., Tatar, M. Pequegnat, C., 2010. Seismic imaging of the lithospheric structure of the Zagros mountain belt (Iran). In: Leturmy, P., Robin, C., (eds) Tectonic and Stratigraphic Evolution of Zagros and Makran during the Mesozoic-Cenozoic. Geological Society, London, Special Publications, 330, 5-18.

Pérez-Gussinyé, M., Watts, A.B., 2005.The long-term strength of Europe and its implications for plate forming processes. Nature. 436, 381-384. doi:10.1038/nature03854.

Sepehr, M., Cosgrove, J.W. 2004. Structural framework of the Zagros fold-thrust belt, Iran. Marine and Petroleum Geology. 21, 829-843.

Silver, P.G., 1996. Seismic anisotropy beneath the continents: probing the depths of geology. Annu. Rev. Earth Planet. Sci. 24, 385-432.

Simons, F.J., van der Hilst, R.D., 2003. Seismic and mechanical anisotropy and the past and present deformation of the Australian lithosphere. Earth Planet. Sci. Lett. 211, 271-286.

Simons, F.J., Zuber, M.T., Korenaga, J., 2000. Isostatic response of the Australian lithosphere: estimation of effective elastic thickness and anisotropy using multitaper spectral analysis. J. geophys. Res. 105, 19163-19184.

Smith, W.H.F., Sandwell, D.T., 1997. Global seafloor topography from satellite altimetry and ship depth soundings, Science, 277, 1956-1962.

Stö cklin, J., 1968. Structural history and tectonics of Iran: a review. Bulletin of the American Association of Petroleum Geologists 52, 1229-1258.

Stö cklin, J., Ruttner, A., Nabavi, M., 1964. New data on the Lower Paleozoic and Pre-Cambrian of north Iran, vol. 1. Geological Survey of Iran. 29 pp.

Swain, C.J., Kirby, J.F., 2003. The coherence method using a thin anisotropic elastic plate model. Geophys. Res. Lett. 30 (19), 2014 (doi:10.1029/2003GL018350). 
Tassara, A., Swain, C., Hackney, R., Kirby, J.F., 2007. Elastic thickness structure of South America estimated using wavelets and satellite-derived gravity data. Earth and Planetary Science Letters. 253: 17-36.

Timoshenko, S.P., Woinowsky-Krieger, S., 1959. Theory of Plates and Shells. McGraw-Hill. $580 \mathrm{pp}$.

Turcotte, D. L. Schubert, G., 2002. Geodynamics, 2nd ed. Cambridge University Press, Cambridge, England, 2002, 456 pp.

Vernant, P., Nilforoushan, F., Hatzfeld, D., Abassi, M.R., Vigny, C., Masson, F., Nankali, H., Martinod, J., Ashtiani, M., Bayer, R., Tavakoli, F., Chéry, J., 2004.Present-day crustal deformation and plate kinematics in the Middle East constrained by GPS measurements in Iran and northern Oman. Geophys. J. Int. 157, 381-398.

Watts, A.B., 2001. Isostasy and Flexure of the Lithosphere.Cambridge Univ. Press.

Zamani, A., Agh-Atabai, M., 2009.Temporal characteristics of seismicity in the Alborz and Zagros regions of Iran, using a multifract alapproach. Journal of Geodynamics. 47, 271-279. Zamani, A., Hashemi, N., 2000. A comparison between seismicity, topographic relief, and gravity anomalies of the Iranian Plateau. Tectonophysics 327, 25-36.

Zamani, B., 2009. Study of tectonic stress state of Iran, unpublished Ph,D thesis. Shiraz University. Shiraz. Iran.

Zamani, B., Angelier, J., Zamani, A., 2008. State of stress induced by plate convergence and stress partitioning in northeastern Iran, as indicated by focal mechanisms of earthquakes. J. Geodyn. 45, 120-132.

Zanchi, A., Berra, F., Mattei, M., Ghassemi, M., Sabouri, J., 2006. Inversion tectonics in Central Alborz, Iran. Journal of Structural Geology. 28, 2023-2037. 
Zoback, M.L., 1992. First- and Second- Order Patterns of Stress in the Lithosphere: The World Stress Map Project. Journal of Geophysical Resarch. 97, 11703-11726. 


\section{Figure captions}

Fig. 1. Generalized tectonic map of Iran superimposed on topography. KFZ: Kazeroun Fault Zone, MFZ: Minab Fault Zone, SSMB: Sanandaj- Sirjan Metamorphic Belt and UDMB:

Urumieh-Dokhtar Magmatic Belt (modified and adapted from Stö cklin, 1968; Alavi, 1991;

Kaviani et al., 2009).

Fig. 2. Map showing the locations of the gravity stations in Iran, (Dehgani and Markis, 1984).

Fig. 3. Two dimensional Map showing the mechanical anisotropy in Iran. Axes are drown in the direction of $\mathrm{T}_{\min }$ with length (i.e., strength of anisotropy) proportional to the percent anisotropic coherence effect $(\mathrm{PACE})=100\left(\mathrm{~T}_{\max }-\mathrm{T}_{\min }\right) / \mathrm{T}_{\max }$.

Fig. 4. Comparison between weak axes of the mechanical anisotropy, shown in yellow and green thick bars (averaged over a $160 \times 160$ and 320 × $320 \mathrm{~km}$ area) and averaged maximum and minimum horizontal stress directions, shown by brown and blue arrows, respectively. Stress directions have been calculated from the earthquake focal mechanisms in Iran (Zamani et al., 2008; Zamani, 2009).

Fig. 5. Histogram showing directional differences between the weak axes of the mechanical anisotropy and the averaged maximum horizontal stress axes in each seismotectonic stress province (symbols as shown in figure 4).

Fig. 6. Shows the weak axes of the mechanical anisotropy (thin blue lines) averaged over an $80 \mathrm{x}$ $80 \mathrm{~km}$ area and the non-null measurements of seismic anisotropy (green thick bars) (Kaviani et al., 2009). 


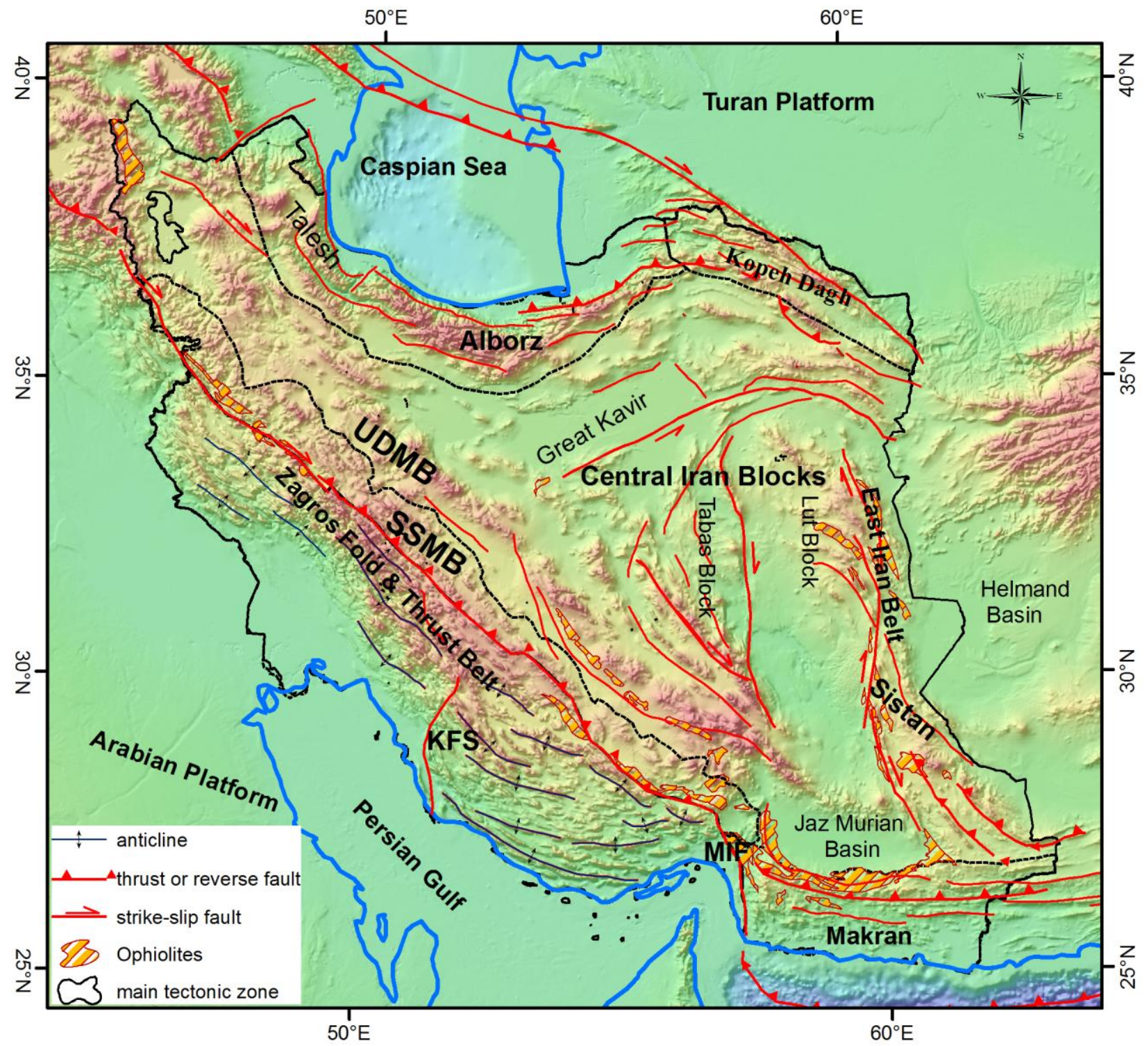

Fig. 1 


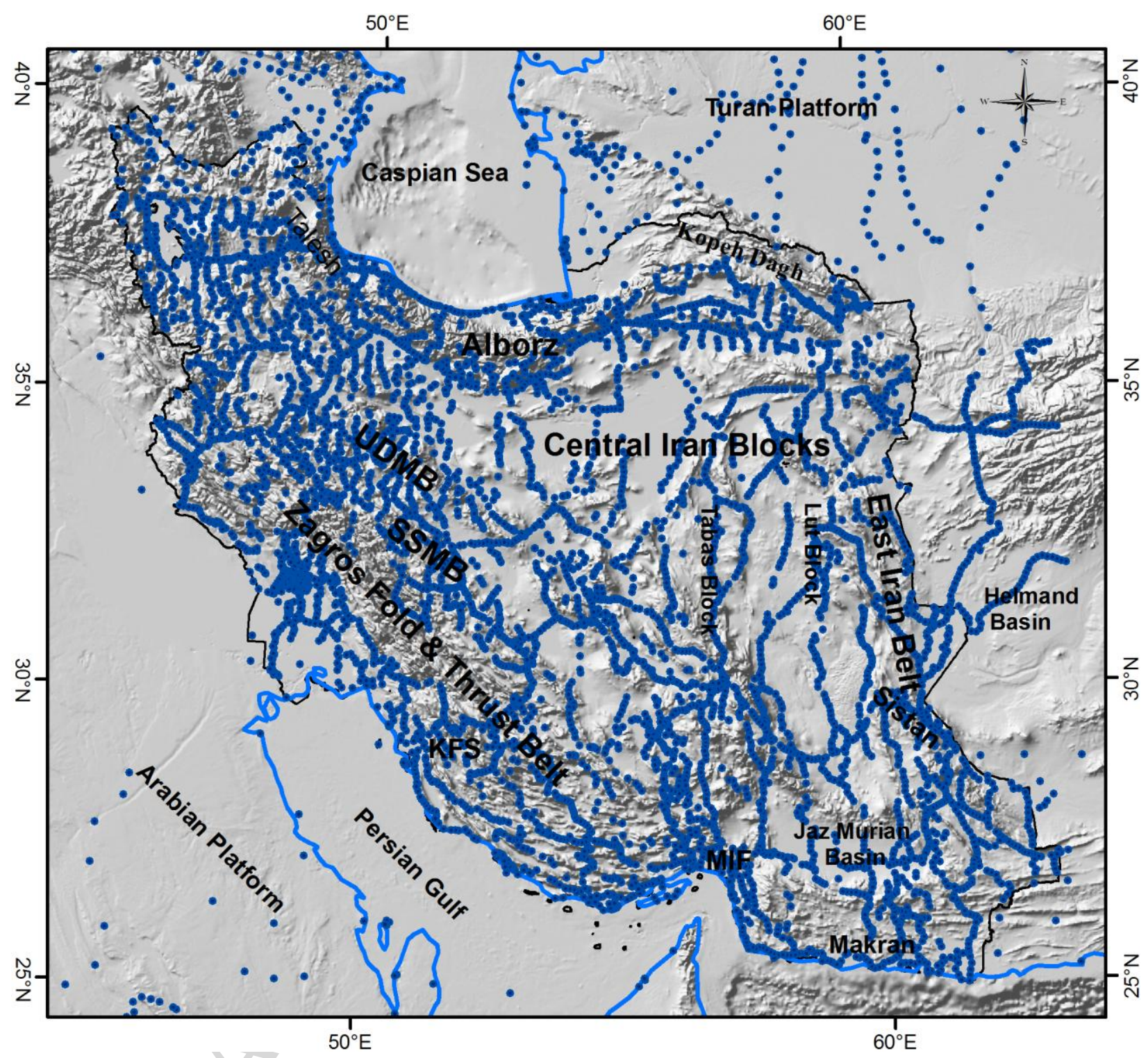

Fig. 2 


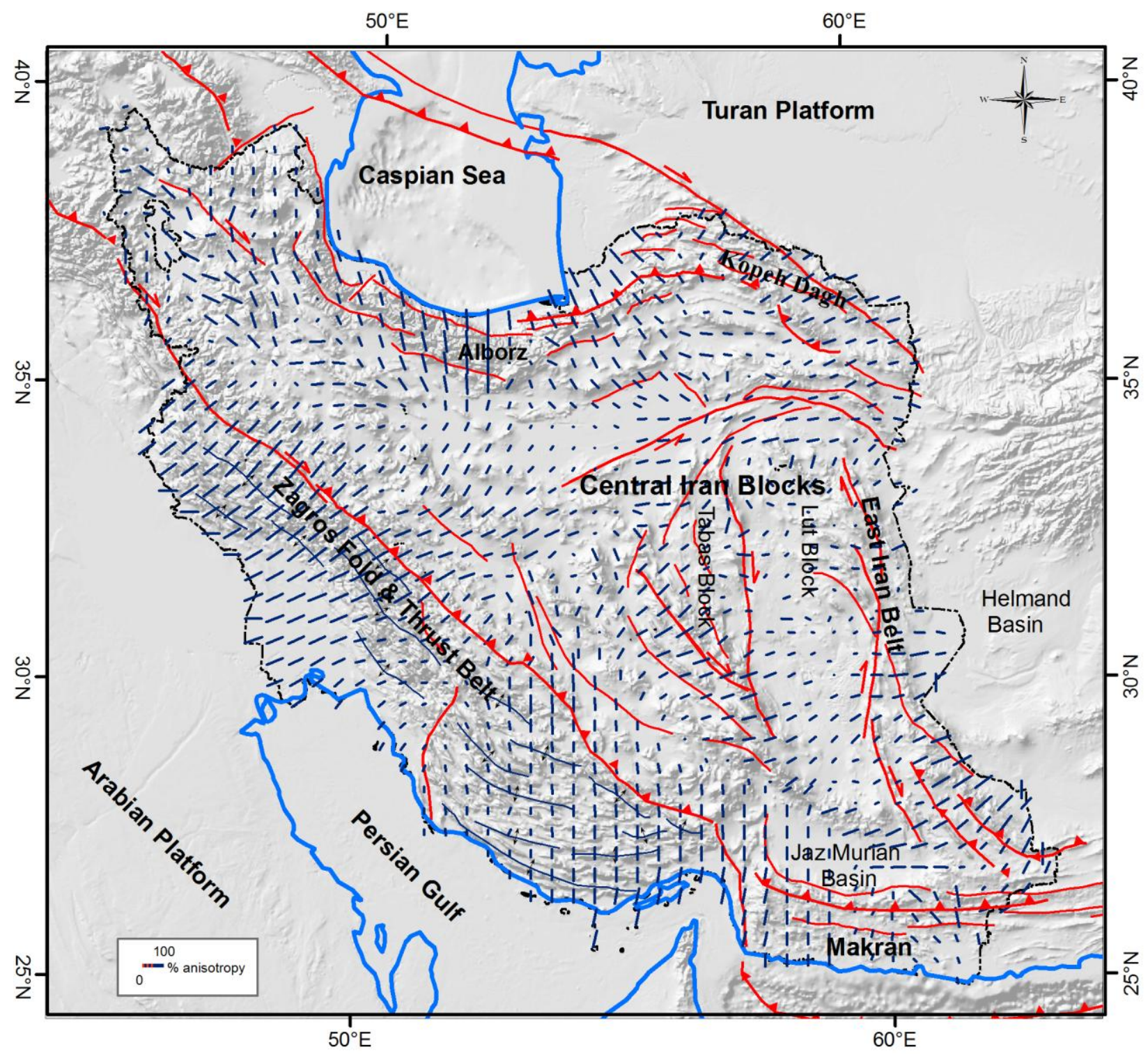

Fig. 3 


\section{ACCEPTED MANUSCRIPT}

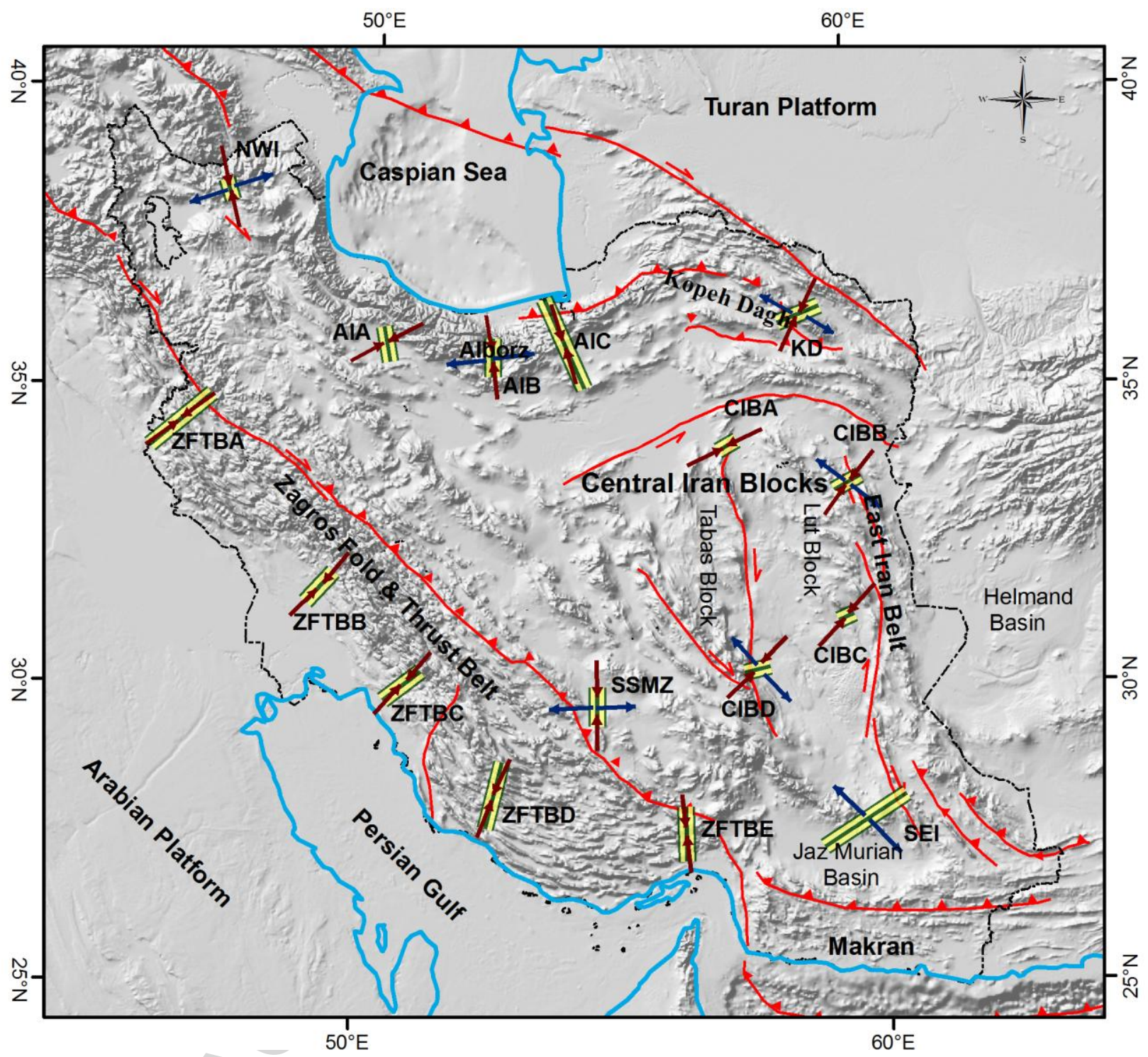

Fig. 4 


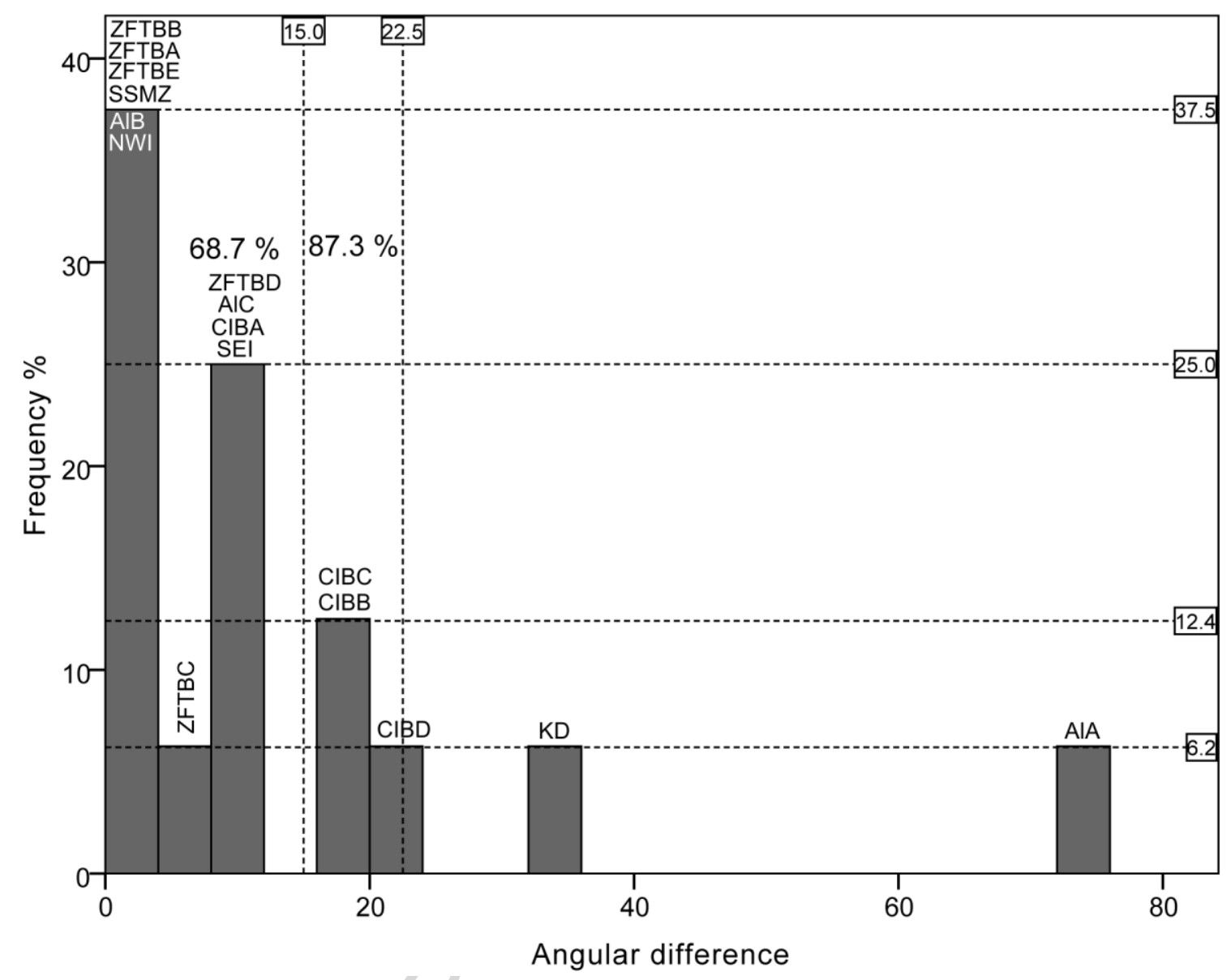

Fig. 5 


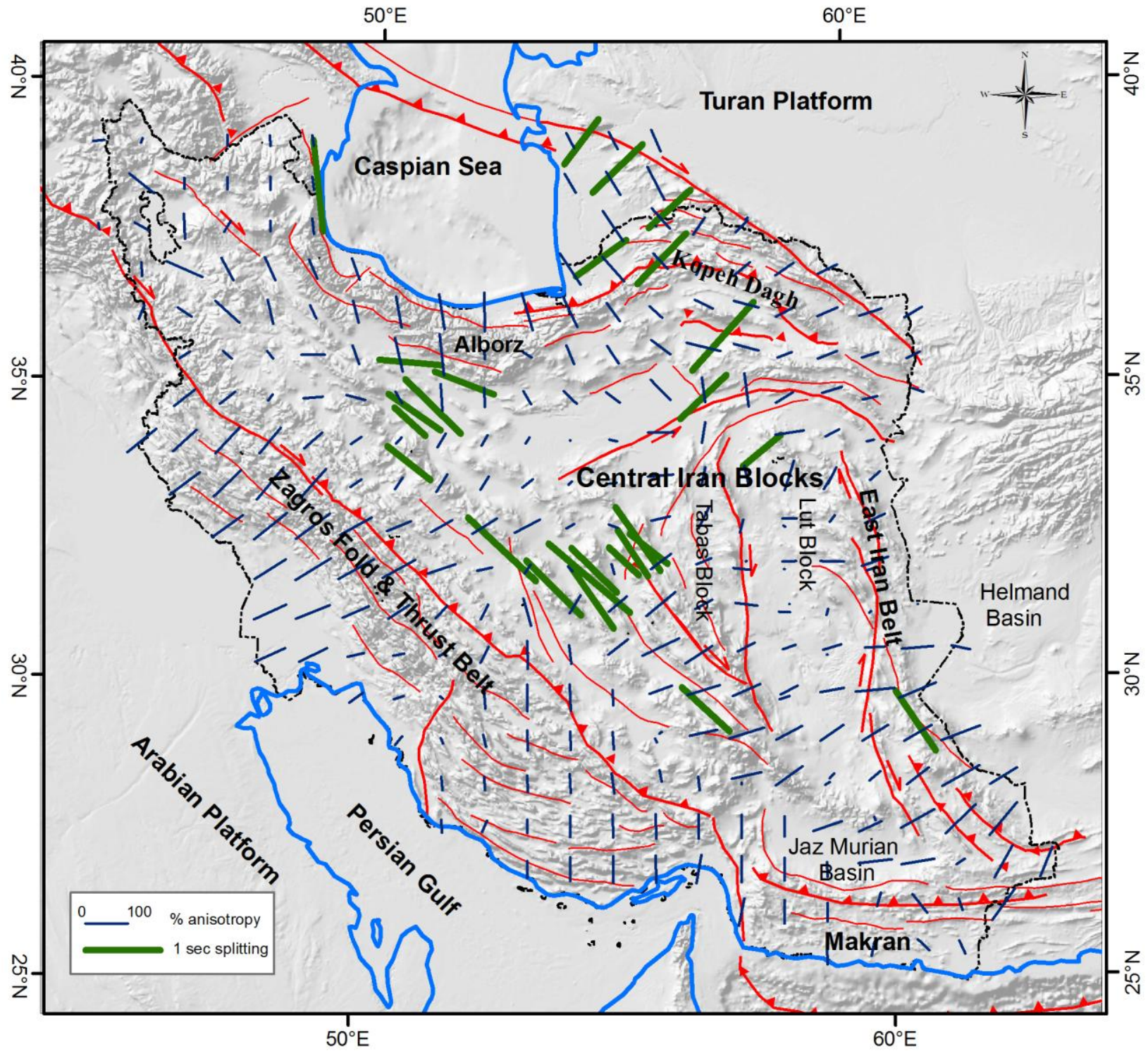

Fig. 6 


\section{Highlights}

- A map of mechanical anisotropy in the lithosphere in Iran has been presented.

- The present day stress field and the frozen strain in the lithosphere are still related.

- All levels of the lithosphere in Iran are coherently deformed.

- Pre-existent structures mainly control the mechanical anisotropy of the lithosphere. 